\title{
Covid-19: Pandemic is having "severe" impact on non-communicable disease care, WHO survey finds
}

\section{Owen Dyer}

Montreal

The covid-19 pandemic has dramatically curtailed the provision of health services for non-communicable diseases, says a survey of 155 countries by the World Health Organization conducted over three weeks in May. ${ }^{1}$

Non-communicable diseases (NCDs) killed about 41 million people last year, $71 \%$ of all deaths worldwide. About 15 million people aged 30 to 69 die each year from an NCD, and $85 \%$ of these premature deaths occur in low and middle income countries.

In the survey poorer countries were the most likely to report disrupted services, but some $94 \%$ of responding countries had reassigned health ministry staff from work on NCDs to dealing with the pandemic. Hypertension treatment has been partially or completely disrupted in $53 \%$ of the countries surveyed, diabetes treatment in $49 \%$, cancer treatment in $42 \%$, and cardiovascular emergency responses in $31 \%$ of countries, the survey found.

In the Netherlands, new cancer diagnoses have fallen by $25 \%$ since the pandemic lockdown began. In rural India, 30\% fewer cardiac emergencies reached health facilities in March 2020 than the previous year.

Rehabilitation services, which are often key to a healthy recovery after severe covid-19, have been disrupted in $63 \%$ of countries surveyed. Screening campaigns have been put on hold in more than half.

WHO's director general, Tedros Adhanom Ghebreyesus, said, "The results of this survey confirm what we've been hearing from countries for a number of weeks now. Many people who need treatment for diseases like cancer, cardiovascular disease, and diabetes have not been receiving the health services and medicines they need since the covid-19 pandemic began. It's vital that countries find innovative ways to ensure that essential services for NCDs continue, even as they fight covid-19."

Progress in curbing NCDs has dwindled since 2010, and the world was already off course to meet its sustainable development goal of reducing premature deaths by a third before 2030 . Post-pandemic health services will need an NCD plan to regain the ground lost, says WHO.

World Health Organization. Preliminary results: rapid assessment of service delivery for noncommunicable diseases during the COVID-19 pandemic. 29 May 2020. https://www. who.int/who-documents-detail/rapid-assessment-of-service-delivery-for-ncds-during-thecovid-19-pandemic.

This article is made freely available for use in accordance with BMJ's website terms and conditions for the duration of the covid-19 pandemic or until otherwise determined by BMJ. You may use, download and print the article for any lawful, non-commercial purpose (including text and data mining) provided that all copyright notices and trade marks are retained.

https://bmj.com/coronavirus/usage 